Kansas State University Libraries

New Prairie Press

\title{
A New Normal: Young Men of Color, Trauma and Engagement in Learning
}

Joni M. Schwartz

Follow this and additional works at: https://newprairiepress.org/aerc

Part of the Adult and Continuing Education Administration Commons

(c) (i) (8)

This work is licensed under a Creative Commons Attribution-Noncommercial 4.0 License

\section{Recommended Citation}

Schwartz, Joni M. (2012). "A New Normal: Young Men of Color, Trauma and Engagement in Learning," Adult Education Research Conference. https://newprairiepress.org/aerc/2012/papers/41

This is brought to you for free and open access by the Conferences at New Prairie Press. It has been accepted for inclusion in Adult Education Research Conference by an authorized administrator of New Prairie Press. For more information, please contact cads@k-state.edu. 


\title{
A New Normal: \\ Young Men of Color, Trauma and Engagement in Learning
}

\author{
Joni M. Schwartz, Ed.D.
}

\begin{abstract}
This phenomenological study examined trauma experienced by young men of color, trauma's effect on engagement in college, and the young men's willingness to access counseling. The theoretical and methodological frameworks are Critical Race Theory (CRT) and Cultural Historical Activity Theory (CHAT) respectively. The findings from the study presented in this paper suggest that young men have a "lived experience" of trauma that they perceive as normal which impacts their engagement in learning.

\section{Introduction}

In almost every quantitative analysis involving significant demographics such as unemployment, poverty, high school and college non-completion, incarceration, access to health care and life expectancy, young men of color are statistically significant. Now, in the early part of the $21^{\text {st }}$ century, in each of these areas we find "distressing statistics regarding the unfavorable disparities of black males." (Franklin, 2006). The educational disparity is evident in the oftreported findings that there are more black males in jail than in college. In 2008, black males age 18 and older accounted for $5 \%$ of the college population, but $36 \%$ of the prison population (Bureau of Justice Statistics, 2008; Current Population Survey, 2009). More recently, U.S. congressman, Michael Honda, while starting a National Dialogue on Equity, quotes President Obama, and others who have called the issue of young men and engagement in education one of the "greatest civil rights issues of our time" (Honda, 2011)

These inequities are part of a larger social context and linked to ongoing psychological wounds caused by traumatic experiences for many young men of color that further complicate both the injury and the healing necessary for optimal engagement in GED and college. This qualitative study examines the relationship between young men of color, trauma and their engagement in learning providing a deeper narrative than can be gleaned from solely quantitative analysis. The findings of this work, and others like it, indicate that many of our young men of color are coming to the educational setting with past trauma, Post Traumatic Stress Disorder (PTSD) that impacts their engagement in learning (Noguera, 2003; Curry, 2010).

\section{Review of Literature}

A strong correlation between crisis or trauma and psychological distress has been recognized for years, (Allen 1995; Choy and Bosset, 1992; Manson, 1996; Perry, 2000; Schwartz and Perry, 1994; Wolf and Mosnaim, 1990). Statistics indicate that People of Color are more likely to be victims of crime and violence (Washington, D.C.: Bureau of Justice Statistics, 2009), and in particular, "Men and boys of color have more than twice the risk of witnessing domestic violence, suffering child abuse and neglect or having an incarcerated parent." (Davis, L., 2009), and that homicide is the leading cause of death among young black males (CDC report, 2010) evidences the extent to which young black males are exposed to trauma, both directly and vicariously. Racial trauma, or what Carter and Helms (2002) term, "race-based traumatic stress disorder" describes a specific type of trauma that is unique to young men of color. We cannot deny our country's tarnished past when considering the plight of young black males. "Few scholars can argue against the concept that Black manhood in America is deeply rooted in the
\end{abstract}


slave experience and the period of Jim Crow segregation.” (Van Thompson, 2010, p.xii). In Black Outlaws, Van Thompson referenced Martin Luther King Jr. who made clear how, “America's racist culture of violence and disrespect makes Black peoples' existence a day-to-day battle, leaving them in a constant state of anguish and anxiety. Moreover, there is a transgenerational trauma in which the psychological impact is passed on to succeeding generations." (Van Thompson, p. 22).

Of particular importance is to remember how White Americans have been systematically taught to not display overtly racist acts or to use language indicative of prejudicial thought, and consequently, may presume that racism is rare or a thing of the past. (Constantine, Smith, Redington, \& Owen, 2008). However, it is the repression of blatantly racist behaviors that has led to the adoption of other racial behaviors that are often subversive and have been shown to be equally damaging, if not more so. These behaviors, known as "racial microaggressions" (Constantine et al., 2008; Sue, Nadal, Cappodilupo, Lin, Torino \& Rivera, 2008), imply assumptions of several themes: intellectual inferiority, second-class citizenship, criminality, inferiority status, universality of the African American experience, and superiority of White cultural values and communication styles. (Sue et al., 2008).

Of specific interest to this study is work around educational trauma. Pedro Noguera discusses the educational environment many people of color encounter in their middle school/high school years: "Students living in inner-city neighborhoods, travel to school with the very real threat of violence every day." Writing about one of his school studies, Noguera pinpointed a very revealing and important observation that is critical, especially for White counselors and educators who work with students of color: "I became increasingly aware of the fact that many adults at this school had no idea of how kids experience violence in their everyday lives." (Noguera, 2003). In "Engaging Out of School Males in Learning" (Schwartz, J), the correlation between past educationally negative experiences and engagement in GED and college is explored suggesting that affective mentoring relationships, like those developed in counseling relationships, are key to school re-engagement. (2010)

\section{Theoretical Framework}

This study uses Critical Race Theory (CRT) as the lens through which young men's lived past and present experiences of trauma and engagement in higher education were interpreted. CRT is a theoretical framework that purports that race must be a component in any discussion of education or counseling, and it cannot be separated from a larger social context. But any discussion of race is full of contradiction and complexity particularly as it is institutionalized, including the institutionalized disparity in educational opportunity which is both an issue of civil rights and social justice (Heaney, 2000). In addition, CRT emphasizes the importance of the voices of people of color (Delgado and Stephancic, 2001), the experiences of microagressions (Pierce, C.) and the centrality of experiential knowledge through counter-storytelling (Solorzano 1998). In relation to adult and higher education, critical race theorists see themselves involved in transformation of the current inequitable educational system to one that contributes to the success of all people of color. (Ladson-Billings, 2005; Closson, 2010).

Research Question

\section{Research Design and Methods}

This qualitative phenomenological study attempted to answer the question: "How does trauma experienced by young college age men of color affect their learning engagement and their access 
of college counseling services?" For purposes of this study, trauma is defined as: an injury done to personhood (Diane Langberg, 2003) manifested in experiences that are emotionally painful and distressing and that overwhelm a person's capacity to cope. Bessel van der Kolk and his colleagues describe this incapacitation as overwhelming ... the pairing of rage and powerlessness is thus a pairing of opposite forces. (Wineman, 2003).

\section{Participants}

A homogeneous, criterion based sampling was sought, the criterion being: men of color, enrolled in college at the time of initial consent to participate, 18-28 years old who had either accessed counseling services because of trauma, or who had spoken or written in their classes about traumatic lived experiences. Twenty participants were recruited from two large urban public colleges on the East Coast, one a four year and the other a community college. Participants were both GED and high school graduates

\section{Positionality}

In the tradition of phenomenological research, epoch or bracketing by the researchers was done. (Moustakas, 1994) However, both co-researchers had a collective 45 years of working with college age young men in adult education, or higher education settings in urban classrooms, counseling, or research settings. Our understanding as White researchers of the prevalence and the power of "White privilege" was also pertinent. With this positionality, we attempted to make operative both personal and epistemological reflexivity (Willig, C. 2001) and to examine the ways in which our involvement with this particular study influenced, acted upon and informed the study itself. (Nightingale and Cromby, 1999). However, the reflexivity was hard work reminiscent of Pillow's "reflexivities of discomfort." (Pillow, 2003)

\section{Data Collection}

As is the research tradition for a psychological phenomenological study, this project utilized in-depth semi-structured interviews with open-ended questioning and an initial focus group as the primary data collection methods. Interviews were of approximately 45 minutes in length and were conducted with nine of the twenty young men. Initial interviews were videotaped with follow-up interviews being either videotaped or interview notes were taken utilizing an interview protocol sheet for documentation. An initial focus group of 75 minutes in duration was conducted with eleven of the participants and utilized the same questions and semi-structured format as the individual interviews but adapted to a group setting. A secondary data collection method was also utilized. The unedited videotaped footage of all interviews and focus groups was viewed by an additional focus group of five participants who responded to the data footage.. This group was then videotaped during their discussions; this data was then added to the collection for analysis as well. It is important to note that this secondary data collection method served both as additional data and as member-checking. (Lincoln, Guba, 1985).

\section{Data Analysis}

The study followed these phenomenological data analysis steps: horizonalization, clustering, single-subject analysis and inter-subject analysis and the role of context to finally capture the essence of the lived experience of trauma, education and accessing counseling for young men of color. Cultural historical activity theory (CHAT) was used as the methodological framework to 
sort, cluster the data into the seven CHAT components: subject, object, mediating artifacts, community, rules, division of labor and outcomes. This categorizing of the data was then used in analysis.

- Developed initially from the work of Russian cognitive psychologist, Lev Vygotsky (1978) as a constructivist theory, CHAT has both psychological and socio-cultural underpinnings. CHAT allows the research a wide lens embracing complex systems including issues of race, marginalization, history, and culture (Ladson-Billings, Tate, 1995) providing for the possibility of an integrative and unified research approach

Validity

For the purpose of establishing research validity, two methods were employed: memberchecking (Lincoln \& Guba, 1985) and methods triangulation. Following preliminary data analysis, as stated previously, research participants were invited to review both the video footage of their interviews and focus groups and respond to final descriptive written analysis. During this member checking focus group, participants had an opportunity to correct errors and challenge what may have been perceived as wrong interpretations as well as affirm other interpretations of the data.In addition to the member checking, two types of triangulation were used:

methodological and investigator triangulation. Methodological triangulation involved the convergence of data from interviews, focus groups, and journaling (memoing). The investigator triangulation included the analysis of data from two researchers as well as the researcherparticipant corroboration during member checking. The two authors of this study both analyzed data using the CHAT framework and used this as a cross-examination of the findings. (Denzin, 1978).

\section{Findings}

There are four findings from this study that have potential impact for the way educators understand young men of color, as well as possible impact on how college counselors structure counseling sessions and services. The findings include: the perception that trauma is a normal part of life, young men's skepticism of college counselors ability to help, participants reported benefits of counseling once engaged, and the effectiveness of all male educational group writing and discussions. For purposes of this paper, only the first and fourth findings will be discussed.

\section{A New Normal}

Data suggests that for young men of color in this study, trauma is not an event but an ongoing, in some instances almost daily, series of experiences. This was born out by the collective responses of all 20 participants. The term "new normal" describes the persistent and cumulative traumatic experiences of our young men in and out of school that they described as "normal" in their lives. From the young men's experience it is a lived experience that needs to be "accepted" as part of life. Without exception, all of the young men of color in this study resonated with this term, understood trauma as "a given" in their lives, and accepted the inevitability of it.

Specifically as it surrounds educational trauma - trauma experienced in school or before and after school- participants reported trauma experienced in middle school or high school with the perpetrators being peers or teachers. These experiences of trauma included, but were not limited to, verbal abuse in the form of ongoing name-calling, bullying, condescending and demeaning language by teachers and school official; physical abuse - gang beatings, threats with weapons, shootings, witnessing violent deaths of friends and classmates; educational abuse - inappropriate 
special education placements, chaotic and out of control classrooms, and criminalization of school settings. In their own words research participants spoke about this trauma. Kaliym, now a college freshman, described his experiences in previous educational settings: "I never felt safe in school, elementary, junior high, high school." Philippe, a college sophomore, spoke about his educational trauma:

"Bullied, beaten, robbed... but others had it worse than me. The beaten ups that I've seen, always fights, gang activity, there is no quiet day at high school. If you get home, it's a blessing. I'm out of high school now so I don't have to worry about guns and knives."

The participants reported these events with a clarity and with detail almost as if they had happened yesterday. Data indicates that although many of these experiences occurred in previous educational settings, the impact of these experiences are still current as they engage in higher education classrooms. Data also is clear that some of these experiences continue to occur in college settings although with not the same frequency.

Rilwan, a college freshman, described his past educational experiences with visible anger: I'm not going to lie. I do care what people think of me. I cried. Fights, bullying." Triston's experiences surrounded his interaction with teachers:

Teachers said to us, 'I don't care if you don't learn, I still get paid'. Teachers don't care. No motivation. Teachers basically told us the answers...made me feel stupid, a little lower."

Beyond educational trauma, the young men spoke of other types of traumatic experiences as if they were talking about eating dinner or going to the store. In their own words they spoke of the following experiences with most often a conversational style and resignation in their tone of voice connoting that this is the way life is. Philippe stated:

"Tension, trauma on the street, need to watch my back.... I've been through stress. Stress. I take it as this is nothing to me. Pain is nothing"

For Kareem, his experiences spanned from instances in a White high school to incarceration.

'Nigger' was written on my locker, I got violent, would fight. I was in jail at age 17, surrounded by grown men. I

was raped. I got violent, gangs, in solitary confinement."

Denzil related instances of peer loss:

"Losing people - it happens a lot. A guy I grew up with got shot-the second friend death in a year. I lost my best friend and my cousin was killed."

Findings seem to indicate that young men of color's experience with trauma is unique because it is cumulative, persistent, and transgenerational. Van Thompson addresses the 
"psychological violence of slavery" and how many Black men "fight an internal war with America's racism which left them with deep psychological scars." (2010, pp. 62, 50). As bell hooks argues, "Psychological factors are at the root of our history under racism and white supremacy... it is the normalization of violence in our lives as Black people that creates the foundation for ongoing trauma reenactment." (hooks, p. 21) Rilwan, speaks to this type of trauma:

"White students called me names. Some were funny, but they stick...I acted on it in anger. I use to beat up students"

Kareem expressed his feeling this way: "White kids go to college. Black kids go to jail." And Jamal described his experiences with racism in other words: "A whole system telling you you're something else."

As stated previously, although much of the educational trauma happened in previous school experiences, the interview and focus group responses were 'fresh'. The young men remembered and reported still having trauma responses. Participants reported that when they came into college classrooms they often "scoped" the room to make sure it was safe. Participants described how they chose to sit in the back of the room to make sure that everything was Ok before they engaged with the teacher and other students. Participants reported friends dropping out of school rather than be fearful. Participants report that these past experiences affect their engagement in college and in learning making them less trustful, less assertive, and wary of educational settings. But they also report that their current college environment is generally both physically and emotionally safer than past school experiences, but they still report being hesitant to engage

\section{Group Discussion and Writing for Young Men of Color}

During the course of the research focus and member checking groups, data revealed that although many of the young men said that they did not and probably would not go to counseling; nevertheless, they appeared to enter into a therapeutic discussion. Originally groups were scheduled for one hour, but groups ran well over the time because the young men did not want to stop and seemed verbally and non-verbally engaged. Comments were made by participants that they enjoyed the group very much, felt open and transparent to share their traumatic experiences, and that they felt "relieved" and very good after the group. Comments were also made saying how "grateful" they were to have been a part of the group talking about their lived experiences.

Data further suggests that these research groups were therapeutic to the young men because they were all male groups (except for one researcher), all shared the same type of traumatic experiences, felt that their experiences as men of color was unique, and that the group was insular and confidential enough to allow them to express emotion around the trauma they had experienced. Jamal, after attending a member checking focus group that viewed the unedited footage from previous interviews with young men, responded:

"It is easy to talk among ourselves..... to know that we all think about this stuff, all have gone through. I'm not the only one. It gives hope......" hearing others - all the struggle and persevering through it is very uplifting." 
During the course of data collection, the focus and member checking group participants repeatedly vocalized about how the groups were important to them individually and how they felt open to share their deep feelings and wanted their voices to be heard by others. Jamal articulates some of these sentiments around the groups:

[They] gave me a forum to express my concerns about the hardships and struggles I face because of my race.... [this] has helped me grow into a better person.

Data indicates that the group spaces, focus group discussions, member checking group, and writing groups were a safe space where the young men felt free, emotionally safe to express and talk about traumatic experiences especially as they related to education and traumas' (both past and present) impact on current engagement in college.

\section{Implications for Practice}

The findings of this study indicate that for college age young men of color there is a need to reflect and re-evaluate both college classroom and counseling approaches particularly as we look to initially engage this population. The following recommendations are made in light of the findings of this study and the bulk of literature in the field on retention of young men in educational settings:

- Recognize that young men of color understand their experiences of trauma as normal and need to be able to "rename" these experiences

- Recognize that some of our young men of color are experiencing Post Traumatic Stress by virtue of their past educational experiences, institutional racism and microaggressions, and lived daily experiences

- Engage in "reflexivities of discomfort" (Pillow, 2003) around our own White privilege, and/or class privilege and how that positions us as counselors and educators and what that means as we approach our practice.

- All male group sessions for discussion and writing around educational shows promise for engagement

- Writing and sharing the writing of trauma holds promise for both classroom strategies and a counseling strategy.

Beyond these recommendations, there are implications for further research. A review of the literature and the findings of this study indicate we need to know more about the White counselor and educator working with young men of color, writing the pain with young men, and how to create "spaces" in both college classrooms, GED programs, and counseling settings that make room for the acknowledgement and naming of trauma, and the use of group discussion/writing and counseling's potential role in all male settings.

\section{References}

Allen, J. (1995). Coping with trauma. Arlington, VA: American Psychiatric Publishing. Bureau of Justice Statistics. (2008). A call for change; Current Population Survey. (2009). American Educator. Vol.35, No.1 Spring 2011. P. 17.

Carter, J. \& Helms, J. (2002, September). Racial discrimination and harassment: Race-based traumatic stress. Presented at the American College of Forensic Examiners Conference, 
Orlando, Fl.

Center for Disease Control and Prevention Study(CDC). National Center for Health Statistics. Number 37, May 2010.

Choy, T. \& Bosset, F. (1992).Post-traumatic stress disorder: an overview. Canadian Journal of Psychiatry. 37:8, 578-583.

Closson, R. (2010). Critical race theory and adult education. Adult Education Quarterly.60(3) p. 261-283.

Constantine, M. G., Smith, L., Redington, R. M., \& Owen, D. (2008). Racial microaggressions against black counseling and counseling psychology faculty: A central challenge in the multicultural counseling movement. Journal of Counseling and Development, 86, 348-355.

Curry, J. (2010). Addressing the spiritual needs of African American students: implication for school counselors. The Journal of Negro Education, 79(3), 405-415.

Davis, L. (2009). Reparable harm: Assessment and addressing disparities faced by boys and men of color in California. Santa Monica, CA: Rand Corporation.

Delgado, R., \& Stefancic, J. (2001). Critical race theory: An introduction. New York: NY University Press.

Denzin, N. (1978). The research act: a theoretical introduction to sociological methods. New York: McGraw-Hill.

Franklin, J. (2006). Black men, America and the $21^{\text {st }}$ century. Black male youth: creating a culture for educational success. Presented by The City University of New York. April 26, 2006.

Heaney, T. (2000). Adult education and society. In A. L. Wilson \& E. R. Hayes (eds.), Handbook of adult and continuing education (pp. 559-572). San Francisco: Jossey-Bass.

Honda, M. Preserving the American dream: national dialogue on equity. American Educator. Vol.35, No.1 Spring 2011. p.2.

hooks, bell. (2003). Rock My Soul: Black People and Self-Esteem,New York: Washington Square Press.

Ladson-Billings, G. (2005). The evolving role of critical race theory in educational scholarship. Race Ethnicity and Education, 8(1), 115-119.

Ladson-Billings, G. \& Tate, W. (1995). Toward a critical race theory of education. Teachers College Record. 97(1), 47-68.

Langberg, D. (2003). Counseling survivors of sexual abuse. Nashville, TN: Xulon Press.

Lincoln, YS. \& Guba, EG. (1985). Naturalistic inquiry. Newbury Park, CA: Sage Publications.

Manson, S. (1996). The wounded spirit: a cultural formulation of post-traumatic stress disorder. Medicine and Psychiatry, 20:4, 489-498.

Moustakas, C. (1994). Phenomenological research methods. Thousand Oaks California: Sage Publications.

Noguera, P. (2003). City schools and the American dream : Reclaiming the promise of public education. New York: Teachers College Press.

Perry, B.D. (2000) Violence and children: How persisting fear can alter the developing child's brain. The Child Trauma Academy. www.ChildTrauma.org.

Polkinghorne, D.E. (1989). Phenomenological research methods. In R.S.

psychology:

Valle and S. Halling (Eds.), Existential-phenomenological perspectives in

Exploring the breadth of human experience (pp. 41-60). New York: Plenum Press. 
Schwartz, E. and Perry, B. (1994). The post-traumatic response in children and adolescents. Psychiatric Clinics of North America 17:2 311-326.

Schwartz, J. (2010). Engaging out-of-school males in learning. Rutgers University: New Brunswick. Doctoral dissertation.

Scurfield, R., \& Mackey, D., (2001). Racism, trauma and positive aspects of exposure to racerelated experiences: Assessment and treatment implications. Journal of Ethnic and Cultural Diversity in Social Work, 10, 23-47.

Sue, D. W., Nadal, K. L., Cappodilupo, C. M., Lin, A. I., Torino, G. C., \& Rivera, D. P., (2008). Racial microaggressions against Black Americans: Implications for counseling. Journal of Counseling and development, 86, 259-260.

Solorzano, D. (1998). Critical Race Theory, Racial and Gender Microaggressions, and the Experiences of Chicana and Chicano Scholars. International Journal of Qualitative Studies in Education 11, 121-136.

Wineman, S. (2003) Power under: Trauma and non-violent social change. www.gis.net/ swineman/reactions.html

van der Kolk, B., McFarlane, A., \& van der Hart, O. (1996).A general approach to treatment of posttraumatic stress disorder. In B. van der Kolk \& A. C. McFarlane (Eds), Traumatic stress: The effects of overwhelming experience on mind, body and society) New York: Guilford Press. (pp. 417-440).

Van Thompson, C. (2010). Black outlaws: race, law and male subjectivity in African America literature and culture. New York: Peter Lang Publishing, Inc.

Vygotskii, L. S., \& Cole, M. Z. (Eds.). (1978). Mind in society: The development of higher psychological processes michael cole ... [et al.]. Cambridge: Harvard University Press.

Washington, D.C.: Bureau of Justice Statistics, 2009

Williams, A. \& Justice, M. (2011). Attitudes of African-American males regarding counseling in four Texas universities. Education Vol. 131 No. 1 158-168.

Willig, C. (2001). Introducing qualitative research in psychology: adventures in theory and method. Buckingham: Open University Press. 